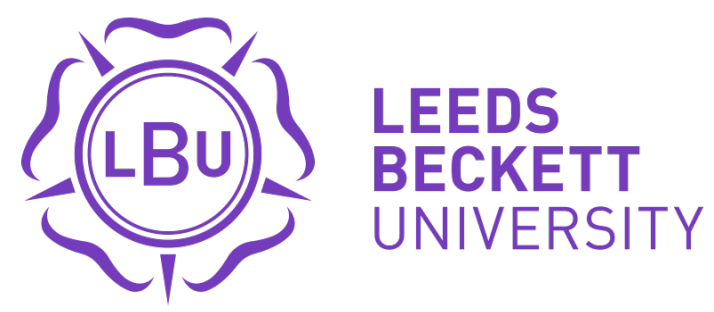

Citation:

Sass, C and Surr, C and Lozano, L (2021) Expressions of masculine identity through sportsbased reminiscence: an ethnographic study with community dwelling men with dementia. Dementia: the international journal of social research and practice. ISSN 1471-3012 DOI: https://doi.org/10.1177/1471301220987386

Link to Leeds Beckett Repository record:

https://eprints.leedsbeckett.ac.uk/id/eprint/7354/

Document Version:

Article (Accepted Version)

The aim of the Leeds Beckett Repository is to provide open access to our research, as required by funder policies and permitted by publishers and copyright law.

The Leeds Beckett repository holds a wide range of publications, each of which has been checked for copyright and the relevant embargo period has been applied by the Research Services team.

We operate on a standard take-down policy. If you are the author or publisher of an output and you would like it removed from the repository, please contact us and we will investigate on a case-by-case basis.

Each thesis in the repository has been cleared where necessary by the author for third party copyright. If you would like a thesis to be removed from the repository or believe there is an issue with copyright, please contact us on openaccess@leedsbeckett.ac.uk and we will investigate on a case-by-case basis. 


\section{Expressions of masculine identity through sports-based reminiscence: an ethnographic study with community dwelling men with dementia}

Sass, C., Surr, C. and Lozano, L.

Abstract

Background

Despite increasing numbers of men living in isolation with dementia in the community, uptake of supportive interventions remains low. This may be because of limited availability of activities suited to men's interests. One organisation reporting higher attendance from men is Sporting Memories, offering inclusive sports-based reminiscence and physical activities for men living with dementia. This study aimed to explore the impact of Sporting Memories intervention on men living with dementia.

\section{Method}

This study was an ethnography employing techniques of participant observation, informal conversations and semi-structured interviews with group participants. Data were woven into a series of narratives using creative non-fiction, to bring life to the first-hand accounts of participants and experiences within a typical group setting.

\section{Findings}

The groups provided an environment for men with dementia to explore, reflect upon and reinforce their masculine identities through the subject of sport. Physical activities further facilitated this embodied demonstration for some, although this was not a feature of all sessions.

\section{Conclusions}

The content of Sporting Memories group sessions provides a vehicle for men to retain an important aspect of personhood. They also hold the potential to present opportunities for men to feel a sense of value by contributing to sessions in varied ways. Facilitators and volunteers require support and training to ensure this benefit is maintained.

\section{$\underline{\text { Keywords }}$}

Dementia; reminiscence; masculinity; masculine identity; sporting reminiscence; ethnography; creative non-fiction; narrative methods

\section{Background}


Gender affects the lived experience of dementia, yet is a neglected dimension in most existing research (Bartlett et al. 2016; Baron, Ulstein and Werheid 2015; Milligan et al. 2016). Although in the minority of those living with dementia, men face distinctive challenges in managing their existing sense of identity (Tolhurst and Weicht 2017), and may react to the effects of their condition in different ways to women (Pearce et al., 2002). A "loss of self" that is prevalent in the dementia discourse can lead to a de-gendering of people living with dementia, therefore, a more sensitive understanding of the gendered experience of men is required (Sandberg, 2018; Tolhurst and Weicht, 2017).

The prevailing (or 'hegemonic') construction of masculinity in Western society is typically associated with attributes including strength, power, control and independence, and is a core component of many men's sense of identity (Canham, 2009). It is ingrained in societal norms and (re)constructed through social interactions (Lohan 2009; West and Zimmerman 1987). The common man is not expected to achieve hegemony in terms of his own masculinity, but the construct represents ideal values (Gough and Robertson 2009). Developing dementia in particular is associated with cognitive and physical impairments which can lead to a perceived loss of place and power in the social world, and carry societal experiences of dehumanisation and stigma (Katsuno 2005; Langdon, Eagle and Warner 2007). Men living with dementia may eventually rely on others to perform and embody aspects of their gendered selves, i.e. grooming rituals (Sandberg, 2018), and may be forced to relinquish existing masculine roles under which men typically frame their identities, such as providing for their households (Bartlett et al. 2016; Calasanti 2003). Upholding one's identity is a crucial contributor to well-being when living with dementia (Kitwood, 1997), and heightened feelings of loss and exclusion may undermine the achievement of well-being with dementia (Bartlett et al., 2016).

In this context, coping with dementia may depend on the psychosocial environment and the processes men believe will best preserve their masculine identity (Robertson 2006; LozanoSufrategui et al. 2018), and they may attempt to emphasise and participate in activities that provide continuity in their masculine self (Canham 2009). However, men are less likely to utilise professional health services or seek psychosocial support than women (Beach and Bamford, 2014). This may be because many community-based activities are tailored to the needs and interests of women with dementia (Bartlett, 2007; Gleibs et al., 2011). Thus, there is a growing trend towards providing supportive group interventions tailored to men. For example, the 'Men's Sheds' movement involves skills-based activities such as DIY and allotment work (Milligan, 2015). Men are encouraged to communicate "shoulder-to-shoulder", enabling them to maintain their identities as workers and express emotions gradually with trusted peers (Milligan et al., 2013; 2015). Other benefits include 
engaging in humorous banter and camaraderie, often a prominent feature of social interactions in the past (Gleibs et al., 2014; Kinney et al., 2011).

A popular recreational activity among many men is playing and following sport (Bruun et al., 2014; Davis and Duncan, 2006). Sports can be tightly interwoven with formative life experiences (Schofield and Tolson, 2010) and being part of a team can reinforce identity, personal value, and offer acceptance (Weiss, 2001). Harnessing men's interest in sport can facilitate uptake of physical and mental health interventions (Bruun et al., 2014; Carone et al., 2016; Curran et al., 2017), and football clubs become vessels to share public health messages with men (Pringle et al. 2014; LozanoSufrategui et al. 2019).

In dementia care, reminiscence has gained popularity as a structured activity which combines social interaction with opportunities to revisit life-defining memories. This can be an enjoyable mechanism for people with dementia to express and maintain identity before others (Woods et al. 2018). Generalised reminiscence can lead to improvements in the quality of one-to-one social interactions, thus strengthening a person's ability to maintain social bonds (Serrani Azcurra, 2012; Brooker and Duce, 2000; Woods et al. 2018). Furthermore, the structured and socially-engaged nature of group reminiscence may derive greater benefits for wellbeing than usual group leisure activities such as dancing, board games, or crafts (Brooker and Duce, 2000). Skilful facilitation and selection of lighthearted subject matter is important to prevent the emergence of painful memories during reminiscence (Anderson and Weber, 2015). Nonetheless, to date there have been no adverse impacts of reminiscence reported for people living with dementia, other than associated impact on caregiver stress (Woods et al., 2018).

During the last decade, the potential benefits of reminiscence have been increasingly harnessed alongside the power of sport to engage men living with dementia. Sports-based reminiscence has shown potential for improved outcomes in well-being, communicative abilities and cognition (CollPlanas et al., 2017; Watchman et al., 2015; Schofield and Tolson, 2010; Wingbermuehle et al., 2014). Previous evaluations of group sporting reminiscence have indicated that men express pride when others recognise their sporting expertise (Coll-Planas et al., 2017; Watchman et al., 2015), but have offered no exploration into the significance of promoting these attributes for masculine identity.

The use of a range of media and memorabilia during generalised reminiscence, such as photographs, artefacts or music (Ashida 2000; Hagens, Beaman and Ryan 2003; Smith et al. 2009) can stimulate discussion and rejuvenate the experiences and emotions associated with past life events (Goldsmith 1996; Schofield and Tolson 2010). Such resources can add value to the sensory and atmospheric experiences of sporting reminiscence; performances of masculinity among groups of men is 
ubiquitous within the milieu of sporting events, for both players and supporters (Ashmore, 2017; Scott, 2020).

Sporting reminiscence has grown in popularity in the UK through community-based group sessions, run by the Sporting Memories Network (SMN, 2019), which incorporate reminiscence with sportsbased discussion and physical activities. The groups are free to attend and advertised online, via social media, and leaflets provided at local venues (e.g. libraries); although membership predominantly builds through word-of-mouth recommendations. Sessions are aimed at those aged over 50, with a specific focus on those living with dementia, depression and loneliness. Despite a gender-inclusive remit, groups report comparatively higher attendance from men than other community provisions (Clark et al., 2015), and provide an ideal opportunity to explore the potential ways for supporting masculine identity in dementia.

\section{$\underline{\text { Study objectives }}$}

Using existing community-based Sporting Memories groups in the UK, this study aimed to determine what attending a group meant to men living with dementia, and to explore potential benefits of attendance.

\section{Method}

This ethnographic study drew on multiple methods: observations, informal conversations, semistructured interviews and reflexive researcher accounts. Ethnography provided a mechanism to understand participants' meaningful experiences, by exploring their interactions within their natural social environments (O'Reilly 2012).

Adopting the role of observer-as-participant enabled the researcher (CS) to become familiar with the group environment and customary practices within the Sporting Memories settings. Subsequently, the role of participant-as-observer gave insight into the views of attendees as events unfolded and the social interactions among group members and facilitators (Marshall and Rossman 2014; O'Reilly 2012). Moving along the participant observation continuum provided an opportunity to include the experiences of individuals with communication difficulties who were unable to participate in formal interviews (Surr et al., 2020). Observations were recorded alongside accounts of conversations as fieldnotes (Fetterman, 1998), which contained detailed descriptions of events, features of the setting, individual reactions and social interactions. The lead author attended weekly sessions over the fieldwork period, planning time flexibly to observe participants arriving and leaving, and recorded their thoughts and reactions to the setting as a novel participant (Marshall and Rossman, 2014). 
Semi-structured interviews were conducted before or after sessions in private spaces at the group venue, participants' homes, or via telephone based on preference. Participants with dementia were offered dyadic interviews with spouses or friends if preferred. Interview questions asked about participants' connection to sport and the impact of Sporting Memories on their lives, helping to contextualise observational data (Fetterman, 1998). Follow-up interviews took place on an ad-hoc basis to explore any developments in thinking or individual circumstances during fieldwork.

\section{Sampling and participants}

Fieldwork took place between January 2018 and February 2019 within five Sporting Memories groups in the north of England, over a period of four to eleven months. Weekly sessions lasted between 90 minutes and two hours, amounting to 150 total observation hours. Features of the participating groups are included in table 1 below.

Purposive sampling was used to identify potential groups in discussion with a senior member of staff from the Sporting Memories network. Groups were prioritised based on their potential to represent a variety of venues and structural models, to ensure sample diversity (Braun and Clarke 2013), and those known to have men living with dementia attending.

Group members were eligible to take part in observations and/or interviews if they were willing to give informed consent and could adequately comprehend the study information. However, men in attendance without capacity also had important contributions to make. Given the variety of ways in which individuals can provide insights through an ethnographic methodology, individuals lacking capacity to give informed consent were included on the advice of a personal consultee (HRA, 2019). Semi-structured interviews and observations were carried out with 46 people, including 10 dyads comprised of a man living with dementia and their spouse/friend. A further five people took part in observations only. Demographics are provided in table 1 below.

Table 1: Interview participant demographics

\begin{tabular}{lll} 
Participant type & Number of participants & Age range (mean) \\
Men with dementia & 12 & $59-82(73)$ \\
\hline Spouses (all female) & 13 & $60-82(71)$ \\
Additional group members (all male) & 9 & $64-75(70)$ \\
Facilitators/volunteers & $12(5$ male) & $23-79(51)$
\end{tabular}


Members of groups were also purposively sampled; a formal diagnosis of dementia was not deemed necessary given the exploratory nature of this study, and commensurate with the non-clinical setting. Instead, individual cases of suspected or diagnosed dementia were confirmed during conversations with group leaders and attendees. Observations and conversation data gave context to each person's condition in place of formal assessment of severity. Individuals were invited to participate once the researcher had taken time to become familiar with the setting and group members, typically after the fourth visit.

Attendance and demographic composition of each participating group are summarised in Table 2 .

Table 2: Number of participants in attendance and roles at participating groups

\begin{tabular}{|c|c|c|c|c|c|c|c|}
\hline $\begin{array}{l}\text { Group } \\
\text { number }\end{array}$ & Setting & $\begin{array}{c}\text { Mean } \\
\text { no. of } \\
\text { men } \\
\text { living } \\
\text { with } \\
\text { dementi } \\
\text { a per } \\
\text { week (\%) }\end{array}$ & $\begin{array}{c}\text { Mean no. } \\
\text { other male } \\
\text { participant } \\
\text { s per week } \\
\quad(\%)\end{array}$ & $\begin{array}{l}\text { Mean no. } \\
\text { female } \\
\text { participant } \\
\text { s per week } \\
\quad(\%)\end{array}$ & $\begin{array}{l}\text { Mean no. } \\
\text { facilitator } \\
\text { s per } \\
\text { week (\%) }\end{array}$ & $\begin{array}{c}\text { Facilitator } \\
\text { type }\end{array}$ & $\begin{array}{c}\text { Frequenc } \\
\text { y of } \\
\text { Physical } \\
\text { activities }\end{array}$ \\
\hline 1 & Library & $4(27 \%)$ & $8(53 \%)$ & $2(13 \%)$ & $1(7 \%)$ & $\begin{array}{c}3 \\
\text { organisatio } \\
\text { n staff } \\
\text { (rota) }\end{array}$ & None \\
\hline 2 & $\begin{array}{l}\text { Footba } \\
\text { II } \\
\text { groun } \\
\text { d }\end{array}$ & $2(10 \%)$ & $10(50 \%)$ & $5(25 \%)$ & $2(10 \%)$ & $\begin{array}{c}1 \\
\text { organisatio } \\
\mathrm{n} \text { staff }+1 \\
\text { volunteer }\end{array}$ & $\begin{array}{c}30 \text { mins; } 1 \\
\text { session a } \\
\text { month or } \\
\text { fewer }\end{array}$ \\
\hline 3 & Library & 7 (32\%) & $3(14 \%)$ & $7(32 \%)$ & $4(18 \%)$ & $\begin{array}{c}5 \\
\text { volunteers }\end{array}$ & $\begin{array}{l}20 \text { mins } \\
\text { Weekly }\end{array}$ \\
\hline 4 & $\begin{array}{l}\text { Footba } \\
\text { II } \\
\text { groun } \\
\text { d }\end{array}$ & $2(25 \%)$ & $4(50 \%)$ & 1 (13\%) & $1(13 \%)$ & 1 volunteer & None \\
\hline 5 & $\begin{array}{l}\text { Footba } \\
\text { II } \\
\text { groun } \\
\text { d }\end{array}$ & 5 (15\%) & 17 (52\%) & 7 (21\%) & 5 (15\%) & $\begin{array}{c}5 \\
\text { volunteers } \\
+2 \text { support } \\
\text { staff }\end{array}$ & $\begin{array}{c}45 \text { mins; } \\
1-2 \\
\text { sessions } \\
\text { per } \\
\text { month }\end{array}$ \\
\hline
\end{tabular}


Ethical approval was obtained from the local NHS Research Ethics Committee in December 2017 (reference: 17/YH/0366), and all participants gave informed consent to take part. Individuals lacking capacity to provide informed consent were included if they had a personal consultee able to give advice on their wishes to take part.

Analysis

Data analysis involved a reflexive iteration of Thematic Analysis (TA) (Braun and Clarke 2006; Braun and Clarke 2013), which offered flexibility to accommodate the depth and breadth of the data and research aims (Braun and Clarke 2006). The application of TA involved thorough engagement with the data; beginning with transcription of interviews and elaboration of observational notes, before ongoing interpretation and familiarisation with the prepared data. Codes were then applied to portions of text which provided relevant context in relation to the research questions. This involved the triangulation of codes across transcripts, field notes and reflexive researcher accounts. 'Patterns of meaning' or themes were systematically highlighted among the coded data and explored across the full dataset (Braun and Clarke 2013). Priority was given to latent themes which painted a picture of the meaning and impact of Sporting Memories in participants' lives.

Use of TA led to powerful and salient concepts, but some of the more compelling stories can become fragmented and obscured when grouping data under themes. For this reason, creative non-fiction (CNF) was utilised to present the data as a narrative piece. This technique can be combined with TA to maintain a sense of the 'whole' when interpreting qualitative data (Carless and Douglas 2017), and can draw ethnographic data together in an accessible form. Stories are products of qualitative enquiry and can therefore be organised using analytical processes such as TA, as is the case in this study (Smith et al., 2015). Stories told following theoretical interpretations exist themselves as theory; they can be blended with existing research findings to demonstrate agreements or contradictions and build a more complex picture of the message conveyed through storytelling (Bloom 2003; Smith, et al., 2015). Further, writing a story provides the opportunity to apply and communicate multiple theories in the same text. Stories add nuance to the temporal and contextual aspects of living with long-term conditions such as dementia and are accessible, facilitating dissemination and dialogue with wide audiences (Smith et al., 2015).

An assessment of trustworthiness criteria from Tracy (2010) was applied in the design and conduct of fieldwork; for example, the first author coded study data and differences in interpretation were resolved through discussion with co-authors. Findings were also shared with participating groups to 
confirm coherence and resonance. Following these criteria ensured the application of rigorous research procedures and the use of self-reflexivity to identify subjective biases, an important consideration of ethnographic research (O'Reilly, 2012).

The results in this paper use CNF to tell a story within a composite, fictional Sporting Memories group, set at a football ground in the fictional town of 'Esterley', and synthesise aspects of the varied participating Sporting Memories groups and the circumstances of individuals who attended. Each CNF is thematically formed of quotations derived from interviews and fieldnotes, descriptions of places and scenarios which 'set the scene', and fictionalised narratives including dialogue to weave the data together (Smith et al., 2015; Caulley 2008). To remain as true to their experiences as possible, the scenarios for each CNF were drawn from real-life activities as discussed by participants.

\section{Findings}

Two themes reflected how Sporting Memories groups supported men to maintain a sense of identity and to share this with others. Physical activities, reminiscence and the social milieu at Sporting Memories groups helped to unlock masculine identity, despite the limitations dementia placed on social interaction for many.

\section{Unlocking identity through Sporting Memories}

Sporting Memories afforded men the opportunity to express their masculine identities through the reminiscence and physical activities carried out in the sessions, as told through the CNF of a husband and wife, Eddie and Angela.

As Eddie and his wife burst into the room and squinted in the light, they shook the raindrops off their sleeves and stared in disbelief at the puddles forming around them. They were greeted with a sympathetic chuckle by Sarah, the club's Sporting Memories group leader as she helped them peel off their coats. The warmth of the players' bar was an instant relief to them both. Eddie took in the brightness of the furnishings, the plush reds clashing with yellow and blue framed club strips adorning the walls. Breathing in the smells of the aged venue, he caught a whisper of Saturday afternoons filled with punters rushing in to warm themselves in the densely-packed queue at the bar. He instantly recognised the aroma of stale beer saturating the carpet from decades of post-match rituals. Eddie and Angela no longer came out for matches these days; the sights and smells took him longer to get used to. 
As the pair took seats along the back row of chairs, Sarah approached them again, holding a bag containing a boccia set against her side with her elbow. "Well done for making it here in this weather guys!" she smiled, giving each a gentle hug with her free arm. She was followed by a small, nervouslooking man, still in his raincoat. The lenses in his glasses had fogged. "Can I introduce you to Charlie? He's here for the first time today. I think you'll have a few old memories in common." she grinned expectantly at the two of them.

"Welcome Charlie!" Eddie shook his hand and smiled. Sarah paused as they made introductions, before nodding in satisfaction and hurrying away to set up the equipment at the far end of the room. Charlie told the pair how he'd planned on attending for a while after his son saw a flyer in the ticket office. His wife had passed away eight months previously, and people had started to say they worried he might be shutting himself away; his family mentioned the word 'depressed' a few times. "I do a couple of things now, walking football... though I can't do too much with my hip the way it is. They said I might enjoy it here too... my son and I have been long-suffering season ticket holders for many years."

With his hunched posture and fixed gaze, Charlie's nerves were there for all to see, but Eddie could tell he was going to like this dry sense of humour. He nodded vigorously. "Oh yes. This group here, has had a positive effect on everybody's lives. There's always some kind of topic I can get interested in. Otherwise you just go to a coffee morning, and they just sit there and talk about... nothing really but they go and have coffee and cake and that. I'm not saying I'm above them but I'm there talking to people on a par with me sort of thing. I can associate myself with-as a sportsman with the people here."

Eddie's enthusiasm put Charlie at ease. He had been in the club bar countless times but it felt alien to him today; he felt too nervous to take in his surroundings. He barely noticed how different the room appeared with games equipment and memorabilia dotted around. Just behind them, a table tennis set had been erected by two volunteers; he hadn't even heard them making a fuss as they struggled to straighten the legs underneath. As the tension dissipated in his shoulders, he allowed himself to look around the room and make eye contact with others as they arrived. People smiled warmly back at him; Charlie came to his senses and turned back to Eddie with a gasp.

"Eddie Graham!" He spluttered. "I can't believe I didn't recognise our star midfielder." He grinned, "Well, Angela says I'm looking a bit 'weathered' these days. I didn't realise she was right."

"What an honour, I can't wait to tell my lad. Do you know what, I always hoped I'd bump into you back in the day."

Eddie grinned, visibly bolstered by Charlie's flattery. 
"Yeah, that missed penalty in the '75 cup final lost me fifty quid... you absolute git."

As Sarah finished making introductions and announcements to the group, the room filled with the noise of chairs shuffling as people stood to get in line for their favourite activities for the morning. Sarah sauntered around the room, proudly taking in the buzz of activity and watching as volunteers encouraged some of the quieter members to join in. Four men were seated inline, poised as they watched the first take his turn to roll a red boccia ball towards the jack at the far end. As it came to a halt just inches away, several onlookers sharply drew breath, watching to see how the next person would play their shot. Jeers and laughter followed as a blue team member threw his ball high in the air, watching it bounce before resting six feet away from its target. He laughed and groaned loudly, sinking his face into his cupped hands in mock embarrassment. Sarah turned to see two men, close friends, playing table tennis. One of the men had shown signs his dementia had progressed recently. His shots kept landing away from the table, and his friend seemed to spend most of his time fetching the ball from the floor, often having to take a gentle jog to the far end of the room. He might have missed a tricky return pass, but he was still a challenging opponent. After another couple of minutes, the friend seemed to tire and suggested that they have a rest to see what was happening with the hand cycles. He lay his bat on the table and turned around to walk away, but the man stayed frozen in position at the end of the table. He kept hold of his bat, seeming unsure of what to do next. A few moments passed where he remained staring at nothing in particular; somewhat lost. Sarah made her way over to him, asking if he needed a partner to carry on playing. He said nothing in return, but picked up his bat and served.

"It's great to see everyone up and about like this, everyone having a go." Angela laughed. Sarah smiled. "Yeah, it is. Everyone used to say they preferred it just being a coffee morning, you know chatting and talks and that. It's just that for some people, and I'm thinking about the ones who might have problems communicating and can't just jump in with stuff to say, they get a bit... lost. But since we got this equipment, I think it's good I think they enjoy it you know, they love having a go at the darts and they do archery and stuff like that, I think sometimes, some of them would rather, forego the bit of chat at the start and just crack straight on with the activities. There's a new guy Fred, he didn't really want to get involved but then one of the wives put the boccia balls in his hand 
and he was there playing for quite a while which is what it's all about isn't it. You just push yourself and break that barrier once. I said to Fred's wife, I could tell he's played darts all his life cos he's just got a natural dart player's throw you know. I've seen days when he's got sort of five or six hundreds in a row. His wife said he's always been competitive and it certainly shows."

At that moment, Angela looked around the room to see Fred looking down at a set of darts in his hand, a concerned expression on his face. He wobbled slightly as he stepped up to a line of tape on the floor. In one fluid movement, his first dart glided through the air before becoming firmly lodged in the double-twenty spot. The volunteer overseeing the game led a cheer for Fred, who looked around with a bashful smile on his face, as if he hadn't noticed his audience before. Two more high-scoring throws followed, before Fred stepped a little more confidently towards the board, retrieving the darts one by one as the volunteer wrote down each number on his pad. "Ninety-three!" he announced with a smile. Fred grinned back at him with pride.

Thematic summary

Opportunities for men to resume acts of physical coordination and skill were thus important to open up lines of interaction with others within the Sporting Memories groups. The warm welcome, lighthearted and gentle physical activity could facilitate friendly competition and a familiar social milieu for the men attending. Through demonstrating these abilities to others, men experiencing limited communicative abilities could demonstrate retained abilities, generate positive attention and experience a sense of pride. Activities offered during these sessions promoted inclusion and meaningful social interactions among group members and facilitators, providing activity leaders were mindful of participants' abilities and inclination to be involved.

The social power of sporting reminiscence Sporting Memories groups harnessed sports-based reminiscence activities to encourage men to promote their identity. The social interaction during facilitated reminiscence afforded the additional benefit of creating familiar situations among like-minded individuals, reinforcing a shared identity within the group and promoting a sense of belonging.

Eddie and Charlie sat with their heads close together, poring over a pile of clippings from the sports pages of old newspapers, pointing and chuckling at mulleted players from the seventies as Eddie recounted the nicknames he used to bestow on his teammates. Charlie mirrored Eddie's posture, sighing and landing his palm on the table. "It's great this, remembering the good old days." Both 
grinned as Charlie continued. "Things were just better back then, we didn't know it at the time like, but football nowadays... I've lost interest in it really cos of this back passing and all that. Football had a big part in my life, but nowadays it doesn't."

Eddie's gaze shifted into the distance, as images of his glory days flicked through his memory. "Yeah, sometimes the memories are all you've got when you're older and you're not able to go out and recreate them, and if there's somebody there who remembers it it's a shared activity."

Charlie nodded with enthusiasm. "It's like the talks we have here, it's quite interesting when somebody'll sort of, talk about something from their- cos obviously most of the people here remember more stuff from, probably sixties and seventies and stuff like that. And the seventies was when I was starting to get into sport and going to watch it, so, I can relate to quite a few things that people have seen, they were older than me but they were watching as I was starting to watch them." "I think we've all got a lot in common and we've all got lots to say to each other, yeah. It's the camaraderie that goes on here... I know we have a bit of banter but it's just a nice feeling isn't it? It's just like when I was younger and working with my pals in the factory, I loved it. A good craic and the camaraderie, in these meetings... brilliant, just the same sort of camaraderie."

Sarah approached Eddie and Charlie to persuade them to give their new archery set a try. After some mock-protesting and eye-rolling, she stood looking on as the two of them got to grips with the equipment. Angela returned from the drinks station, snacking on a chocolate biscuit. "Oh fantastic! I haven't tried archery in years." She watched them playfully pretend to aim at each other before nodding towards Fred as he waited for his next turn at darts. "He's still very good at that isn't he? It's like there's some things... you never forget how to do."

Sarah smiled, "Yeah, it's like all the reminiscence we do, I feel like it can rekindle an experience or a sort of, a memory if you like of an enjoyable part of their life. When you speak to people about different topics that they've had in their lives it definitely interests them. It brings them to life, they're beaming." The two of them clapped as Charlie managed to hit the target on his third attempt. His smile vanished as the arrow peeled itself from the board, landing on the floor. Sarah shot a sympathetic look at the fallen arrow, before turning back to Angela, "And it's interesting isn't it to see that some of them can't remember what happened last week but they can remember what happened in 1962 when Esterley won against Rotherham five nil ... it's an incredible experience to go through that memory with them, and I think it benefits them, cos... at the end of the day if they're thinking of what that memory... it's a happy time for them, they're gonna be in a happy frame of mind." 
"And there's so many to choose from you know... Eddie has never stopped talking about his footballing days."

Sarah continued to watch Charlie as he took aim at the target, his face wrinkled in concentration. "But the chaps that do have dementia... they might tell you the same story more than once but to them... every time they tell you it... is the first time they've told you it. But the good thing is... in terms of that person, there will always be another little detail. We had a man who used to be a proper top class referee, and he'd talk about when he was driving home from somewhere and he'd got caught and they realised he was a referee and they let him go, of driving with no lights on or something like that. He told me that story four or five times. And every time he told me it he would add a little bit more detail, he remembered more. So it was great in terms of getting his synapses firing, it was drawing more out of his brain so to speak. So I could ask him a different follow-up question each time. It was definitely worth hearing all four or five variations on the theme, you know?" Angela beamed, her eyes darting back towards Fred. "I do worry sometimes about giving everyone a chance, Fred doesn't usually get a word in with these strong characters." Sarah paused thoughtfully. "I try to bring them in to the conversation... and I often feel that I don't take enough steps actually to do that, yeah. You will notice that if it's not engaging them they will go silent or just smile... but if they're smiling they're fairly happy. But you don't wanna put anybody on the spot too much by going "you, what does that mean to you?" We just go around the table and if they've got nothing to say about it they've got nothing to say about it, so you don't wanna force it. But you just try and provide as many varied things as possible and hope that you spark something." "Yeah, of course. Not everyone wants to be the centre of attention in a big group..." A cheer drew Angela and Sarah's attention away momentarily, until they realised that Eddie's last shot was nowhere near the target. Angela winked at her husband. "Better luck next time, dear."

\section{Thematic summary}

The group interactions rekindled evocative memories of sport from men living with dementia. Reminiscence provided a framework for connecting, providing a basis for group participants to learn about others' lives and experiences, drawing them into the social world. Reflecting on vivid sporting memories could stimulate deeper or prolonged engagement. Through sports reminiscence men with dementia were enabled to reveal their personas and experience feelings of normalcy through typically masculine practices of humour and banter (Martin and Lefcourt, 1983; Tolhurst and Weicht, 2017). Shared activities also gave some men the chance to take others under their wings, and gain contributory roles within the group. 
This study shows the benefits of offering sports-based activity to men living with dementia, within an environment promoting inherently male social dynamics. Sporting Memories Groups supported participating men's identities in three distinct ways: (i) by providing opportunities for embodied expressions of masculine identity during physical activities; (ii) through structured exploration of men's experiences and memories and facilitated sharing with others; and (iii) by fostering an environment reflective of familiar homosocial scenarios which allowed men to reinforce their social selves.

Masculinity is context-dependant (Lozano-Sufrategui et al., 2017; Roberston, 2008) and not universally expressed or acknowledged. Masculine identities are often tacit knowledge, and were seldom acknowledged in explicit terms by the participants in this study. An intervention which facilitates the performance of masculine attributes within an inherently male space (such as a sporting facility) (Scott, 2020) may help men living with dementia to normatively express their gender, helping them to feel at ease, to form friendships with one another and encourage shared defining qualities, thus sustaining their personhood (Sandberg, 2018). Groups with a foundation in sport fulfil these conditions for many (Bruun et al., 2014; Lozano-Sufrategui et al., 2018); a masculine sporting atmosphere is not limited to overt expressions of fandom such as crowd engagement and chanting, but can be imbued through minor match-day experiences, such as quiet utterances and withstanding harsh weather conditions (Ashmore, 2017). These subtle sensory characteristics are more readily reflected within Sporting Memories group spaces, such as sports grounds or rooms filled with memorabilia (Coll-Planas et al. 2017; Ramsay and Ramsay 2014).

Male participants' sporting abilities were a source of pride and an important element of their masculine identities. An ability to 'do' is vital for a sense of self in dementia (Kitwood 1997; Phinney, Chaudhury and O'Connor 2007), reflected in theories of embodied agency and the expression of selfhood through physical acts such as appearance and movement (Kontos, 2014; Kontos and Martin, 2013; Twigg and Buse, 2013). Masculinity theory has reflected on the influence of sport in sustaining hegemonic constructs which can be harmful to those excluded by dominant masculinity (Robertson, 2003). However, sport can also create a space for challenging such masculine ideals through supportive practice and participation from men with disabilities and chronic illness (Robertson, 2003). The human form is an embodiment of personhood, allowing a person with dementia to be viewed within their historical and cultural context through physical attributes. Engaging in sport can represent 'body-reflexive practice' as defined by Connell (2005). The way we move through physical activity can represent how we understand the space and others around us, providing physical connection to the social world (Hughes, 2001) and allowing men to showcase their achievements through embodied practice (Robertson, 2003). This bears particular relevance for 
men with dementia, where gesture and physical behaviour may prevail beyond loss of language and other forms of interaction (Hughes, 2001). Men could experience pride and boosted self-esteem from witnessing others marvelling at their skills (Schofield and Tolson, 2010).

The man who found himself alone with his table tennis bat demonstrated the need for others to support social sporting interactions. Without a partner, he lost his frame of reference and was unable to use the equipment by himself. This emphasises the importance of socially inclusive groups in helping individuals to remain social actors and preserve their identities (Fortune and McKeown, 2016; Gillies and Johnston, 2004). Of the five groups taking part in this study, three of these staged little to no physical activities for the duration of the fieldwork phase; instead sessions consisted of presentations, discussions and viewing reminiscence materials. Those lacking the ability to articulate their views in such situations could become disengaged. It is thus important that activities delivered during group reminiscence are engaging, varied and consider the needs of all members. Offering physical activities not only enabled men with dementia to take part in the group, but facilitators took greater notice of their participants in an active session and were observed to interact with them on a deeper level. This reflects the 'meaningful' component of the activities on offer (Kitwood, 1997; Nyman and Szymczynska, 2016). There are however some issues to consider around a group's willingness and ability to deliver physical activities. An over-emphasis on sports or games may limit the opportunities for men to sit and openly communicate, potentially limiting the exploration of topics such as health and wellbeing (Curran et al., 2017; Blake et al., 2018).

The opening paragraphs to the story set the scene for the Esterley FC group, while illustrating the evocative nature of the football ground setting for long-term supporters of the club like Eddie and Charlie. This conveyed a sense of returning to places and pastimes, such as visiting the ground on a match day, which were typical during their younger years. Settings which are familiar or evocative of certain events can stimulate memories and enhance the experience for people living with dementia (Chaudhury 1999; Chaudhury 2003). Previous projects providing sports-based reminiscence involving sessions delivered at sports grounds and museums have noted ways in which these environments offer meaningful visual stimuli (Tolson, Lowndes and O'Donnell 2013; Watchman et al. 2015). The second narrative section builds on this therapeutic potential of reminiscence, describing the benefits of offering such activity to promote well-being, and enable men living with dementia to share their lifelong identity with others. For many people living with dementia, loss of recent memories can make it difficult to communicate existing identity in later life (Alm et al., 2007). Extant research literature has shown how men's displays of sporting knowledge can strengthen feelings of control and empowerment in the social world (Davis and Duncan, 2006; Kennedy, 2000). An additional benefit to framing discussions around the topic of sport was the expanse of opportunities this 
created to raise relevant topics or ask directed questions to generate a response from the men. Quieter group members were still able to demonstrate historical sporting knowledge through facilitated discussion and multisensory cues.

Group facilitators adopted techniques of active listening to encourage men to share their memories. They perceived a therapeutic benefit to such interactions, both cognitively ('getting his synapses firing') and for communicative abilities; a technique known as a 'quilting narrative' approach to communicating with people with dementia (Moore and Davis 2002). Although repetition can be an indicator of dementia (Holzer and Warshaw 2000), using this style of communication in reminiscence can help individuals to construct meaningful personal narratives. Furthermore, significant memories connected to sport could enhance well-being, as they were typically positive (Tolson et al., 2013). Some participants likely experienced limited opportunities to engage with others, given the increasing levels of social isolation within this demographic (Beach and Bamford, 2014; Courtin and Knapp, 2017). Therefore, the Sporting Memories environment can create a vital source of community, self-esteem and wellbeing for men.

An energetic group atmosphere had a positive impact of drawing out some aspects of the men's personalities through displays of humour, overt social interaction or displays of well-being, reflected when Sarah refers to maintaining a 'business as usual' approach to the male-dominated setting. In the groups in this study, such a social atmosphere appeared to promote a sense of normalcy, a central component of preserving the self when learning to cope with dementia (Phinney 1998; Perry and O'Connor 2002). In a study of a programme providing volunteering opportunities in a local zoo for men living with dementia, the interactions and activities taking place during the programme provided a similar sense of regularity for the men (Kinney et al., 2011). The participants were able to slot into previous social roles ("one of the guys") and felt pride through an acquired sense of purpose. Through the familiarity of banter and performances of masculinity in a group scenario, activities opened up new channels of communication and had residual effects at home, stimulating lively discussions with family members (Kinney, Kart and Reddecliff, 2011).

The jokes in some of the groups were associated with a locker-room style of banter. Ridicule and masculine wit can facilitate social bonding between men (Davis and Duncan, 2006). For those men who identified with this masculine sense of humour before developing dementia, inhabiting such circles and responding positively to the humour of the in-group helped to outwardly reinforce their sense of self. Existing theories on the social utility of humour claim it can be a refuge for marginalised groups and provide comfort among people with a shared stigmatising experience (Watts, 2007). The promotion of a specific, hegemonic variety of masculinity through mechanisms 
such as humour can be viewed as a factor of Sporting Memories' success. This may be at the exclusion of alternative masculinities, given the lack of identified intersections with different sexualities and ethnicities in the sample. It may be that a one-size-fits-all approach may not be feasible within a single setting, and therefore a recommendation for future practice would be to offer a range of services that cater for different expressions of masculinity which are appropriately advertised (Lozano-Sufrategui et al., 2018).

Family play a pivotal role in supporting men to express their masculine identity in the face of dementia, through accompaniment and encouraging sustained activity (Fortune and McKeown, 2016; Phinney et al., 2007). In this study, wives and relatives actively projected men's sense of self through sharing stories and facilitating social interactions. Some participants had reduced communicative abilities, which made their partners question their enjoyment of the group sessions; something also reported in previous studies (Chung, 2009; Perrin, 1997). Reassurance from facilitators and fellow group members encouraged their continuing attendance. Men who are confined to their homes may be at risk of feeling 'stuck' (Gleibs et al., 2014, p.268) and lacking in autonomy, thoughts which can only serve to further marginalise men living with dementia.

Sporting Memories groups will not meet the needs or interests of all men with dementia and should not be seen as a panacea for supporting well-being and identity. Some men may have never taken an interest in stereotypical men's activities in the past but may feel that they have no alternative in order to interact with peers (Lozano-Sufrategui et al. 2017). Furthermore, some older men may feel uncomfortable attending interventions with a predominantly physical basis because of frailty, disability or other health complications (Booth et al. 2000; Sallinen et al. 2009). This emphasises the need for supportive interventions to consider and cater for a broad range of potential men's interests and needs; not everyone may feel catered for by a sports-based group, or one based around stereotypically masculine interests.

This study had some limitations. Groups were based in the north of England, and all participants were White British and identified as heterosexual. Whilst this is representative of typical Sporting Memories group membership, this does not reflect the diversity of experiences of the wider population of men affected by dementia. Additionally, individuals were not required to have a formal diagnosis of dementia to take part in this study, therefore it was not possible to undertake any exploration into the specific impact of differential dementia diagnoses on expressions of masculinity. Despite these limitations, these stories reflect a range of experiences in relation to male identity in dementia. This study represents the first known usage of the CNF method in writing research findings from people affected by dementia. Narrative methods of data representation 
offers a sensitive reflection of the experiences of those taking part in this study; opportunities to foster co-production of research with people affected by dementia; and enable the presentation of data in an accessible, evocative way (Fortune and McKeown, 2016). This invites deeper understanding of the topic at hand (Smith et al., 2015). Future work should consider the merit of narrative approaches to explore the broad scope of men's experiences of life with dementia.

Sporting Memories group sessions present numerous opportunities for men to promote their sense of self through social interactions and demonstration of skill and expertise, an important part of masculine identity. Men may also appreciate opportunities to 'give back' and support others, an important mechanism to maintaining social roles and masculine identity. Interventions such as Sporting Memories groups are well-placed to increase the availability of opportunities for men to explore their pre-existing identities in a supportive environment. Such opportunities could promote the citizenship of group members, providing them with the chance to participate in volunteering roles and contribute useful skills for the benefit of others (Bartlett, 2014).

\section{$\underline{\text { References }}$}

ALM, N., DYE, R., GOWANS, G., CAMPBELL, J., ASTELL, A. AND ELLIS, M., 2007. A communication support system for older people with dementia. Computer, 40(5), pp.35-41.

ANDERSON, K. A. and K. V. WEBER. 2015. Auto Therapy: Using Automobiles as Vehicles for Reminiscence With Older Adults. Journal of Gerontological Social Work, 58(5), p469.

ASHIDA, S. 2000. The effect of reminiscence music therapy sessions on changes in depressive symptoms in elderly persons with dementia. Journal of Music Therapy, 37(3), pp.170-182.

BARON, S., I. ULSTEIN and K. WERHEID. 2015. Psychosocial interventions in Alzheimer's disease and amnestic mild cognitive impairment: evidence for gender bias in clinical trials. Aging \& Mental Health, 19(4), pp.290-305.

BARTLETT, R. 2007. 'You can get in alright but you can't get out:' social exclusion and men with dementia in nursing homes: insights from a single case study. Quality in Ageing, 8(2), pp.1626.

BARTLETT, R., 2014. Citizenship in action: the lived experiences of citizens with dementia who campaign for social change. Disability \& Society, 29(8), pp.1291-1304.

BARTLETT, R., T. GJERNES, A. T. LOTHERINGTON and A. OBSTEFELDER. 2016. Gender, citizenship and dementia care: A scoping review of studies to inform policy and future research. Health and Social Care in the Community.

BEACH, B. AND BAMFORD, S.M., 2014. Isolation: The emerging crisis for older men. A Report Exploring Experiences of Social Isolation and Loneliness Among Older Men in England, Independent Age, London.

BLOOM, L. Z. 2003. Living to tell the tale: The complicated ethics of creative nonfiction. College English, 65(3), pp.276-289.

BOOTH, M. L., N. OWEN, A. BAUMAN, O. CLAVISI and E. LESLIE. 2000. Social-cognitive and perceived environment influences associated with physical activity in older Australians. Preventive medicine, 31(1), pp.15-22. 
BOURGEOIS, M., K. DIJKSTRA, L. BURGIO and R. ALLEN-BURGE. 2001. Memory aids as an augmentative and alternative communication strategy for nursing home residents with dementia. Augmentative and Alternative Communication, 17(3), pp.196-210.

BRAUN, V. and V. CLARKE. 2006. Using thematic analysis in psychology. Qualitative research in psychology, 3(2), pp.77-101.

BRAUN, V. and V. CLARKE. 2013. Successful qualitative research: A practical guide for beginners. sage. BROOKER, D. and L. DUCE. 2000. Wellbeing and activity in dementia: a comparison of group reminiscence therapy, structured goal-directed group activity and unstructured time. Aging \& Mental Health, 4(4), pp.354-358.

BRUUN, D.M., BJERRE, E., KRUSTRUP, P., BRASSO, K., JOHANSEN, C., RØRTH, M. AND MIDTGAARD, J., 2014. Community-based recreational football: a novel approach to promote physical activity and quality of life in prostate cancer survivors. International journal of environmental research and public health, 11(6), pp.5567-5585.

CALASANTI, T. 2003. Masculinities and Care Work in Old Age. Gender And Ageing: Changing Roles And Relationships: Changing Roles and Relationships, p15.

CANHAM, S. L. 2009. The interaction of masculinity and control and its impact on the experience of suffering for an older man. Journal of aging studies, 23(2), pp.90-96.

CARLESS, D. and K. DOUGLAS. 2017. Narrative research. The Journal of Positive Psychology: dedicated to furthering research and promoting good practice, 12(3), pp.307-308.

CAULLEY, D. N. 2008. Making qualitative research reports less boring: The techniques of writing creative nonfiction. Qualitative inquiry, 14(3), pp.424-449.

CHAUDHURY, H. 1999. Self and reminiscence of place: a conceptual study. Journal of aging identity, 4(4), pp.231-253.

CHAUDHURY, H. 2003. Quality of life and place-therapy. Journal of Housing for the Elderly, 17(1-2), pp.85-103.

CHUNG, J. C. 2009. An intergenerational reminiscence programme for older adults with early dementia and youth volunteers: values and challenges. Scandinavian Journal of Caring Sciences, 23(2), pp.259-264.

COLL-PLANAS, L., K. WATCHMAN, S. DOMÉNECH, D. MCGILLIVRAY, H. O'DONNELL and D. TOLSON. 2017. Developing Evidence for Football (Soccer) Reminiscence Interventions Within Longterm Care: A Co-operative Approach Applied in Scotland and Spain. Journal of the American Medical Directors Association, 18(4), pp.355-360.

COURTIN, E. AND KNAPP, M., 2017. Social isolation, loneliness and health in old age: a scoping review. Health \& social care in the community, 25(3), pp.799-812.

DAVIS, N.W. AND DUNCAN, M.C., 2006. Sports knowledge is power: Reinforcing masculine privilege through fantasy sport league participation. Journal of Sport and Social Issues, 30(3), pp.244264.

DOUGLAS, K. and D. CARLESS. 2014. Life story research in sport: Understanding the experiences of elite and professional athletes through narrative. Routledge.

FORTUNE, D. AND MCKEOWN, J., 2016. Sharing the journey: Exploring a social leisure program for persons with dementia and their spouses. Leisure Sciences, 38(4), pp.373-387.

GLEIBS, I.H., HASLAM, C., JONES, J.M., ALEXANDER HASLAM, S., MCNEILL, J. AND CONNOLLY, H., 2011. No country for old men? The role of a 'Gentlemen's Club'in promoting social engagement and psychological well-being in residential care. Aging \& mental health, 15(4), pp.456-466.

GLEIBS, I.H., SONNENBERG, S.J. AND HASLAM, C., 2014. "We get to decide": The role of collective engagement in counteracting feelings of confinement and lack of autonomy in residential care. Activities, Adaptation \& Aging, 38(4), pp.259-280.

GOLDSMITH, M. 1996. Hearing the voice of people with dementia: Opportunities and obstacles. London: Jessica Kingsley Publishers.

GOUGH, B. and S. ROBERTSON. 2009. Men, masculinities and health: Critical perspectives. Macmillan International Higher Education. 
HAGENS, C., A. BEAMAN and E. B. RYAN. 2003. Reminiscing, poetry writing, and remembering boxes: personhood-centered communication with cognitively impaired older adults. Activities, Adaptation \& Aging, 27(3-4), pp.97-112.

HILÁRIO, A. P. 2015. Making sense of a changed physical body: Why gender matters at end of life. Journal of aging studies, 33, pp.58-66.

HOLZER, C. and G. WARSHAW. 2000. Clues to early Alzheimer dementia in the outpatient setting. Archives of Family Medicine, 9(10), p1066.

KATSUNO, T. 2005. Dementia from the inside: how people with early-stage dementia evaluate their quality of life. Ageing \& Society, 25(2), pp.197-214.

KINNEY, J. M., C. S. KART and L. REDDECLIFF. 2011. 'That's me, the goother': Evaluation of a program for individuals with early-onset dementia. Dementia, 10(3), pp.361-377.

KITE, M. E., G. D. STOCKDALE, B. E. WHITLEY and B. T. JOHNSON. 2005. Attitudes toward younger and older adults: An updated meta-analytic review. Journal of social issues, 61(2), pp.241-266.

KITWOOD, T. 1997. Dementia reconsidered: The person comes first. Buckingham: Open University Press Google Scholar.

LANGDON, S. A., A. EAGLE and J. WARNER. 2007. Making sense of dementia in the social world: A qualitative study. Social Science \& Medicine, 64(4), pp.989-1000.

LOHAN, M. 2009. Developing a critical men's health debate in academic scholarship. Men, masculinities and health: Critical perspectives, p11e29.

LOZANO-SUFRATEGUI, L., A. PRINGLE, D. CARLESS and J. MCKENNA. 2017. 'It brings the lads together': a critical exploration of older men's experiences of a weight management programme delivered through a Healthy Stadia project. Sport in Society, 20(2), pp.303-315.

LOZANO-SUFRATEGUI, L., A. PRINGLE, J. MCKENNA and D. CARLESS. 2018. 'There were other guys in the same boat as myself': the role of homosocial environments in sustaining men's engagement in health interventions. Qualitative Research in Sport, Exercise and Health, 11(4), pp.494-509.

LOZANO-SUFRATEGUI, L., A. PRINGLE, S. ZWOLINSKY and K. J. DREW. 2019. Professional football clubs' involvement in health promotion in Spain: an audit of current practices. Health promotion international.

MARSHALL, C. and G. B. ROSSMAN. 2014. Designing qualitative research. Sage publications.

MARTIN, R.A. AND LEFCOURT, H.M., 1983. Sense of humor as a moderator of the relation between stressors and moods. Journal of personality and social psychology, 45(6), p.1313.

MILLIGAN, C., D. NEARY, S. PAYNE, B. HANRATTY, P. IRWIN and C. DOWRICK. 2016. Older men and social activity: a scoping review of Men's Sheds and other gendered interventions. Ageing and Society, 36(05), pp.895-923.

MOORE, L. A. and B. DAVIS. 2002. Quilting narrative: Using repetition techniques to help elderly communicators. Geriatric Nursing, 23(5), pp.262-266.

MOSS, S. Z. and M. S. MOSS. 2007. Being a man in long term care. Journal of Aging Studies, 21(1), pp.43-54.

NYMAN, S.R. AND SZYMCZYNSKA, P., 2016. Meaningful activities for improving the wellbeing of people with dementia: beyond mere pleasure to meeting fundamental psychological needs. Perspectives in public health, 136(2), pp.99-107.

O'REILLY, K. 2012. Ethnographic methods. Routledge.

PEARCE, A., CLARE, L. AND PISTRANG, N., 2002. Managing sense of self: Coping in the early stages of Alzheimer's disease. Dementia, 1(2), pp.173-192.

PERRIN, T. 1997. Occupational need in severe dementia: a descriptive study. Journal of advanced nursing, 25(5), pp.934-941.

PERRY, J. and D. O'CONNOR. 2002. Preserving personhood:(Re) membering the spouse with dementia. Family Relations, 51(1), pp.55-62.

PHINNEY, A. 1998. Living with dementia from the patient's perspective. Journal of Gerontological Nursing, 24(6), pp.8-9. 
PHINNEY, A., H. CHAUDHURY and D. L. O'CONNOR. 2007. Doing as much as I can do: The meaning of activity for people with dementia. Aging and Mental Health, 11(4), pp.384-393.

PRINGLE, A., J. HARGREAVES, L. LOZANO, J. MCKENNA and S. ZWOLINSKY. 2014. Assessing the impact of football-based health improvement programmes: stay onside, avoid own goals and score with the evaluation! Soccer \& Society, 15(6), pp.970-987.

RAMSAY, S. and M. RAMSAY. 2014. A football reminiscence group for people with dementia: the Forfar, Kirriemuir and South West Angus experience. Mental Health Nursing, 34(5), pp.32-33.

ROBERTSON, S. 2006. 'Not living life in too much of an excess': lay men understanding health and wellbeing. Health:, 10(2), pp.175-189.

SALLINEN, J., R. LEINONEN, M. HIRVENSALO, T.-M. LYYRA, E. HEIKKINEN and T. RANTANEN. 2009. Perceived constraints on physical exercise among obese and non-obese older people. Preventive medicine, 49(6), pp.506-510.

SANDBERG, L.J., 2018. Dementia and the gender trouble?: Theorising dementia, gendered subjectivity and embodiment. Journal of aging studies, 45, pp.25-31.

SCHOFIELD, I. and D. TOLSON. 2010. Scottish Football Museum reminiscence pilot project for people with dementia: A realistic evaluation. Glasgow: School of Health Glasgow Caledonian University.

SERRANI AZCURRA, D. J. L. 2012. A reminiscence program intervention to improve the quality of life of long-term care residents with Alzheimer's disease: a randomized controlled trial. Revista Brasileira de Psiquiatria, 34(4), pp.422-433.

SMITH, B., K. R. MCGANNON and T. L. WILLIAMS. 2015. Ethnographic creative nonfiction: Exploring the whats, whys and hows. Ethnographies in sport and exercise research. Routledge, pp.7388.

SMITH, K. L., M. CRETE-NISHIHATA, T. DAMIANAKIS, R. M. BAECKER and E. MARZIALI. 2009. Multimedia biographies: a reminiscence and social stimulus tool for persons with cognitive impairment. Journal of Technology in Human Services, 27(4), pp.287-306.

SPORTING MEMORIES NETWORK. 2019. The Sporting Memories Network: Tackling dementia, depression and loneliness through the power of sport. Retrieved from https://www.sportingmemoriesnetwork.com/

THOMPSON, E. H. 2006. Images of old men's masculinity: Still a man? Sex roles, 55(9-10), pp.633-648.

TOLSON, D., A. LOWNDES and H. O'DONNELL. 2013. Harnessing the Heritage of Football: Creating Meaningful Activities and Therapeutic Reminiscence Work with People with Dementia. 2012. AHRC \& SFC Knowledge Exchange Programme Final Report. ISBN 9781905866656.

WATCHMAN, K., D. TOLSON, N. GALLAGHER, L. CAMERON and M. DOYLE. 2015. Football reminiscence for men with dementia in a care home: a 12-week pilot study in Scotland. Alzheimer Scotland Centre for Policy and Practice, University of the West of Scotland, Paisley, available at: www. uws. ac. uk/workarea/downloadasset. aspx.

WATTS, J. 2007. IV. Can't take a joke? Humour as resistance, refuge and exclusion in a highly gendered workplace. Journal of Feminism Psychology, 17(2), pp.259-266.

WEISS, O. 2001. Identity reinforcement in sport: Revisiting the symbolic interactionist legacy. International review for the sociology of sport, 36(4), pp.393-405.

WEST, C. and D. H. ZIMMERMAN. 1987. Doing gender. Gender \& society, 1(2), pp.125-151.

WOODS, B., L. O'PHILBIN, E. M. FARRELL, A. E. SPECTOR and M. ORRELL. 2018. Reminiscence therapy for dementia. Cochrane database of systematic reviews, (3). 
The authors received no financial support for the research, authorship, and/or publication of this article.

Previous distribution and/or publication

An expanded version of this thematic interpretation is available as a doctoral thesis; the version presented in this article has not been published elsewhere.

Declaration of conflict of interest

The authors declare they have no known conflicts of interest in publishing this work. 